\title{
A Randomised Double Blind Comparative Study of Effects of Intrathecal Versus Intravenous Dexmedetomidine as an Adjuvant to Bupivacaine for Spinal Anaesthesia in Lower Limb Orthopaedic Surgeries
}

Authors

Juberahamad Rajjak Attar ${ }^{1 *}$, Naseema Kanase ${ }^{2}$, Kunda Dimble ${ }^{3}$, Soudamini Gandhi ${ }^{4}$, Bilal Mohammad ${ }^{5}$, Tushar Munnoli ${ }^{6}$, Vivek Dokania ${ }^{7}$

${ }_{1,5,6,7}$ Resident, ${ }^{2}$ Professor, ${ }^{3}$ Associate Professor, ${ }^{4}$ Assistant Professor,

Dept. of Anaesthesiology, Krishna Institute of Medical Sciences, Karad, Maharashtra, India

*Corresponding Author

Juberahamad Rajjak Attar

Resident, Dept. of Anaesthesiology, Krishna Institute of Medical Sciences, Karad, Maharashtra, India. Email:drjuber8833@gmail.com, Mobile No: 8087228566

Abstract

Background: Various adjuvants have been used with local anaesthetics to prolong duration and provide post-operative analgesia of spinal anaesthesia. Dexmedetomidine the selective alpha 2 agonist is being currently used as adjuvant to spinal anaesthesia. Objective of study is to assess the effect of dexmedetomidine on onset and duration of anaesthesia and postoperative analgesia.

Method: Sixty patients scheduled for elective lower limb orthopaedic surgeries under spinal anaesthesia belonging to ASA I and ASAII were randomly divided into two groups of thirty each with double blind randomised method.

GROUP IT (Intrathecal)-0.5\%hyperbaric bupivacaine $15 \mathrm{mg}$ with dexmedetomidine $5 \mu \mathrm{g}$ intrathecally.

GROUP IV (Intravenous)-0.5\% hyperbaric bupivacaine $15 \mathrm{mg}$ intrathecally with dexmedetomidine intravenously.

Time of onset and duration of sensory and motor blockade, hemodynamic parameters in perioperative period, time of first requirement of analgesia were observed.

Result: Sensory and motor duration time is significantly longer in group IT than group IV. Duration of complete analgesia was longer in group IT than group IV. There was no significant difference between both the groups in respect to effective analgesia. There is no significant difference between intraoperative HR, $S B P$, and DBP in both groups. There is a significant difference between values of Ramasay sedation score at 10, 30 and 60minutes when group IT compared with group IV, while no significant difference exists at 0 and 90minutes. There is no significant difference between postoperative VAS and highest sensory level.

Conclusion: Intrathecal dexmedetomidine significantly prolongs the duration of sensory and motor block of bupivacaine spinal anaesthesia as compared to intravenous dexmedetomidine, with preserved hemodynamic stability. 


\section{Introduction}

Perioperative pain management has been a major challenge for anaesthesiologists and there has been a constant struggle to bring out the best possible analgesic technique with least side effects.

Regional anaesthesia and analgesia has the potential to provide excellent operating conditions and prolonged post-operative pain relief. ${ }^{1}$ However, post-operative pain control is a major problem because spinal anaesthesia using only local anaesthetics is associated with relatively short duration of action and thus early analgesic intervention is needed in post-operative period. ${ }^{2}$

Various adjuncts such as benzodiazepines, opioids, ketamine, neostigmine and many other drugs have been used with local anaesthetics to provide better post-operative analgesia, thereby facilitating rehabilitation and accelerating functional recovery. ${ }^{3}$ But these adjuvants (especially opioids) are associated with side effects which limit their use.

Dexmedetomidine is a highly selective a2adrenoceptor agonist recently introduced to anaesthesia. Administration of $\alpha 2$-agonists through the intrathecal route by acting as an adjuvant drug to local anaesthetics provided an analgesic effect in postoperative pain without sedation ${ }^{4}$. They potentiate the effect of the local anaesthetic and allow a decrease in the required doses $^{5}$. Its addition to local anaesthetics prolongs the duration of both sensory and motor spinal blockade $^{6}$. Dexmedetomidine when added to intrathecal bupivacaine resulted in prolongation of the duration of spinal anesthesia ${ }^{7}$.

When dexmedetomidine was given intravenously before spinal anesthesia ${ }^{8}$ or as a loading dose followed by continuous infusion during surgery ${ }^{9}$, it also lengthened the duration of spinal anaesthesia. The purpose of this study was to compare the effect of intravenous versus intrathecal low-dose dexmedetomidine on bupivacaine spinal block in patients undergoing lower limb orthopaedic surgery.

\section{Aim and Objectives}

Aim

The aim of this study was to evaluate the effects of dexmedetomidine administered intrathecally or intravenously in prolongation of spinal anaesthesia using bupivacaine in patients undergoing lower limb orthopaedic surgery.

\section{Objectives}

1. Time of onset and duration of sensory and motor blockade.

2. Hemodynamic parameters in perioperative period.

3. Time of first requirement of analgesia.

\section{Material \& Methods}

After institutional ethical committee approval and written informed consent from patient, this prospective randomised comparative study was conducted at Krishna Hospital, Karad. 60 patients aged between 18 and 60 years of ASA Grade I and II undergoing elective lower limb orthopaedic surgeries under spinal anaesthesia were selected. Pre-operative assessment was done one day prior to surgery and relevant investigations were done. Patients who are physically dependent on opioids, on $\alpha-2$ antagonist treatment and who are contraindicated for spinal anaesthesia are excluded.

\section{Methodology}

Study population was randomly divided into two groups, each having 30 patients. Patients were allowed for a period of absolute fasting of at least 8 hours, without (prior) administering premedication. Intravenous (IV) line was secured with 20 gauge IV cannulaand ringer lactate started at $10 \mathrm{ml} \mathrm{kg-1} \mathrm{hr-1.} \mathrm{On} \mathrm{arrival} \mathrm{in} \mathrm{the} \mathrm{operating}$ room, multipara meter anaesthesia monitor were attached, measuring non-invasive blood pressure, continuous electrocardiogram, and pulse oximetry. Basal vital parameters like heart rate (HR), blood pressure, SPO2 were noted.

HR, Systolic blood pressure (SBP), Diastolic blood pressure (DBP), Respiratory rate (RR), $\mathrm{SPO}_{2}$ were monitored at $0,1,3,5,10,20,30$ ,40,50,60,80,100,120,140,160,180minutes. 
In group IT (Intrathecal) $-1 \mathrm{mlkg}-1$ of normal saline bolus over 10 minutes was given intravenously by infusion pump. Then $0.5 \%$ hyperbaric bupivacaine $15 \mathrm{mg}$ ( $3 \mathrm{ml})$ plus $5 \mu \mathrm{g}$ dexmedetomidine was given intrathecally with 25 gauge needle under aseptic precautions. Followed by normal saline infusion $0.5 \mathrm{ml} \mathrm{kg-1} \mathrm{hr-1}$ throughout the surgery.

In group IV (Intravenous)- $1 \mathrm{mcg} \mathrm{kg}-1$ of dexmedetomidine bolus over 10 minutes was given intravenously by the infusion pump. Then $0.5 \%$ hyperbaric bupivacaine $15 \mathrm{mg}(3 \mathrm{ml})$ plus 0.5 $\mathrm{ml}$ normal saline was given intrathecally with 25 gauge needle under aseptic precautions. Followed by dexmedetomidine $0.5 \mathrm{mcg} \mathrm{kg}-1 \mathrm{hr}-1$ was given throughout the surgery with infusion pump.

Assessment of Sensory Blockade: The onset of sensory block was tested by pin prick method using hypodermic needle. The time of onset was taken from the injection into subarachnoid space to loss of pin prick sensation. The highest level of sensory block and time required to achieve it was noted. The duration of sensory block was taken as time from onset to time of return of pin prick sensation to S1 dermatomal area.

Assessment of Motor Blockade: Tested by Bromage (Br) scale. The time interval between injections of drug into subarachnoid space to patients inability to lift the straight extended leg was taken as onset time $(\mathrm{Br} 3)$. The duration of motor block was taken as time of onset to complete regression of motor block, ability to lift extended leg $(\mathrm{Br} 0)$.

\section{Duration of Complete Analgesia and Effective} Analgesia: Duration of complete analgesia defined as time from the intrathecal injection to vas $>0-<4$ and duration of effective analgesia as time to vas $>4$. Analgesics were avoided until demanded by the patient .Post-operative vas was recorded.

The level of sedation was evaluated both intra operatively and post operatively every 15 minutes using Ramsay Level of Sedation Scale till the patient is discharged from post anaesthetic care unit (PACU).
Hypotension (SBP less than $90 \quad \mathrm{~mm} \quad \mathrm{Hg}$ ) bradycardia (HR $<60 / \mathrm{min})$ and post-operative complications like nausea and vomiting were noted and treated appropriately.

Time for first request for postoperative analgesic (duration of analgesia) was noted.

\section{Statistical Analysis}

Statistical analysis was done by descriptive statistics as mean, SD, percentage etc. Comparison of mean values of all parameters under study was done by applying Student's Unpaired ' $t$ ' test at $5 \%$ and $1 \%$ level of significance.

Comparison of all parameters from 0 minute to 120 minutes was done by applying Student's paired ' $t$ ' test at $5 \%$ and $1 \%$ level of significance.

The statistical significance between group IT and group IV were based on $p$ value. $p$ value of $<0.05$ was considered to be statistically significant.

The statistical software namely SYSTAT version 12 (made by Cranes Software's, Bangalore) was applied.

Sample size - calculated by statistical software Open Epi version 3, with power of study 95\% \& confidence interval of $95 \%$, it comes to minimum of 19 in each group, but I have selected sample size of 30 in each group.

\section{Results}

There was no significant difference between age, height and weight distribution of both the groups as shown in table 1. Group IV showed significant decrease in mean values of pre induction HR from $0 \mathrm{~min}$ to $10 \mathrm{~min}$. While, in group IT no significant decrease in HR seen. $(\mathrm{p}=0.001)$ as shown in graph 1. Group IV showed significant decrease in mean values of pre induction SBP from $0 \mathrm{~min}$ to $10 \mathrm{~min}$. While, in group IT no significant decrease in SBP seen. $(\mathrm{p}=0.001)$ as shown in graph 2. Group IV showed significant decrease in mean values of pre induction DBP from $0 \mathrm{~min}$ to $10 \mathrm{~min}$. While, in group IT, no significant decrease in SBP seen $(\mathrm{p}=0.001)$ as shown in graph 3 . There is no significant difference between mean values of sensory onset and motor onset as shown in table 2 . 
There was significant difference between sensory recovery and motor recovery of both the groups. Sensory and motor duration time is significantly longer in group IT than group IV as shown in table 3. There was significant difference between both groups. Duration of complete analgesia was longer in group IT than group IV as shown in table 4. There was no significant difference between both the groups in respect to effective analgesia as shown in table 5. There is no significant difference between intraoperative HR in Group IT and Group IV as shown in graph 4. There is no significant difference between intraoperative SBP in Group IT and Group IV as shown in graph 5. There is no significant difference between intraoperative DBP in Group IT and Group IV as shown in graph 6. There is a significant difference between mean values of Ramasay sedation score at $10 \mathrm{~min}, 30 \mathrm{~min}$ and $60 \mathrm{~min}$ when group IT compared with group IV, while no significant difference exists at 0 and $90 \mathrm{~min}$ as shown in table 6 and graph 7 . There is no significant difference between postoperative VAS as shown in graph 8 . There is no significant difference between highest sensory levels of both the groups as shown in graph 9. There is no significant difference between both groups in relation to side effects as shown in graph 10 .

Table No.1: Age, height, and weight distribution in Group IT and Group IV:

\begin{tabular}{|l|c|c|c|c|}
\hline & Group IT $(\mathrm{n}=30)$ & Group IV $(\mathrm{n}=30)$ & $\begin{array}{c}\text { Student's } \\
\text { Unpaired 't' test } \\
\text { value }\end{array}$ & 'p' value \\
\cline { 2 - 4 } & Mean \pm SD & Mean \pm SD & 0.23 & $\mathrm{p}=0.14$ \\
\hline Age in years & $46.73 \pm 13.20$ & $46.80 \pm 12.58$ & 0.14 & $\mathrm{p}=0.21$ \\
\hline Height in feet & $5.38 \pm 0.40$ & $5.34 \pm 0.42$ & 0.49 & $\mathrm{p}=0.64$ \\
\hline Weight in Kgs. & $60.87 \pm 17.27$ & $65.03 \pm 9.78$ & 0.79 \\
\hline
\end{tabular}

Graph 1- Comparison of Pre Induction HR

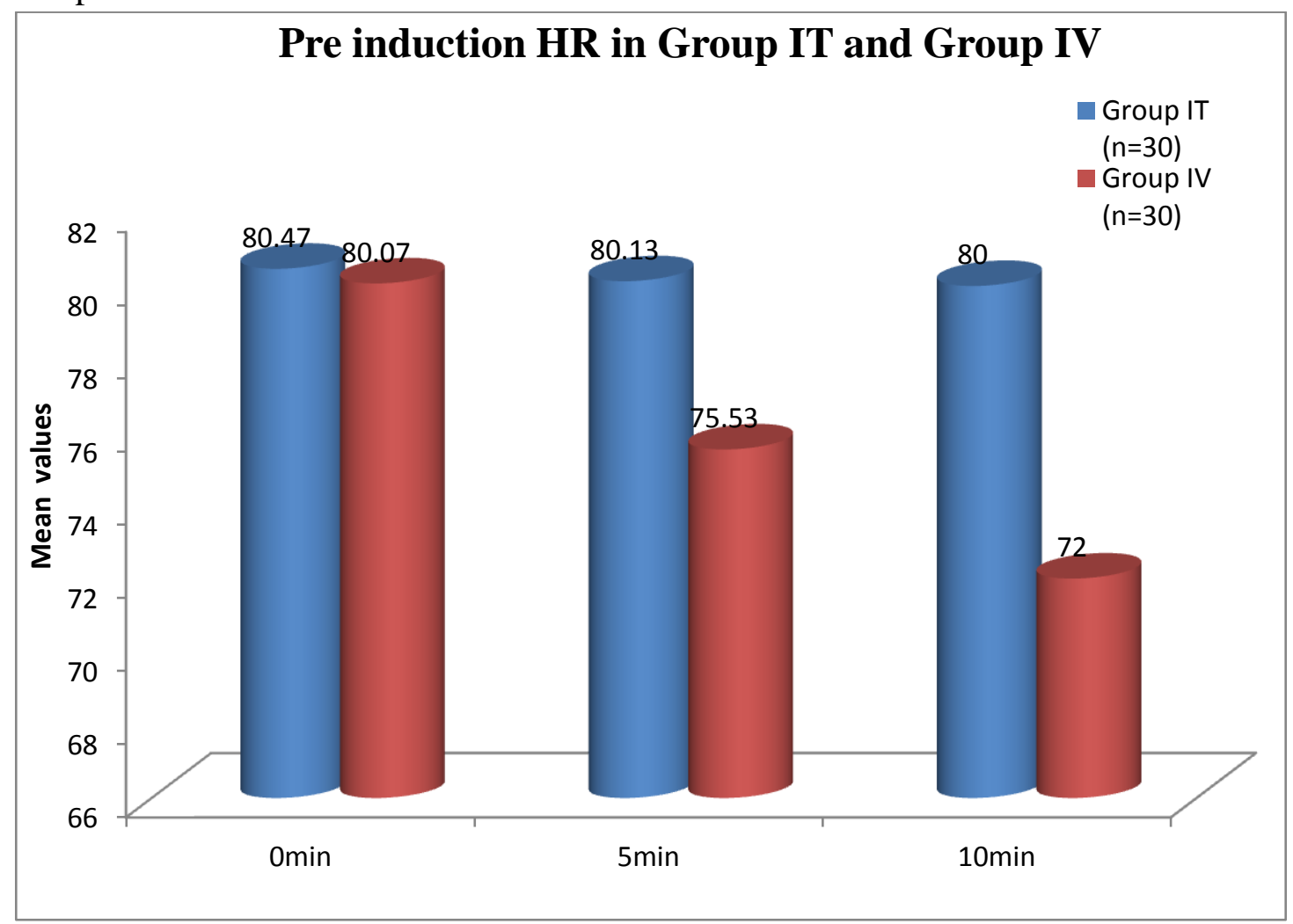


Graph 2- Comparison of Pre Induction SBP

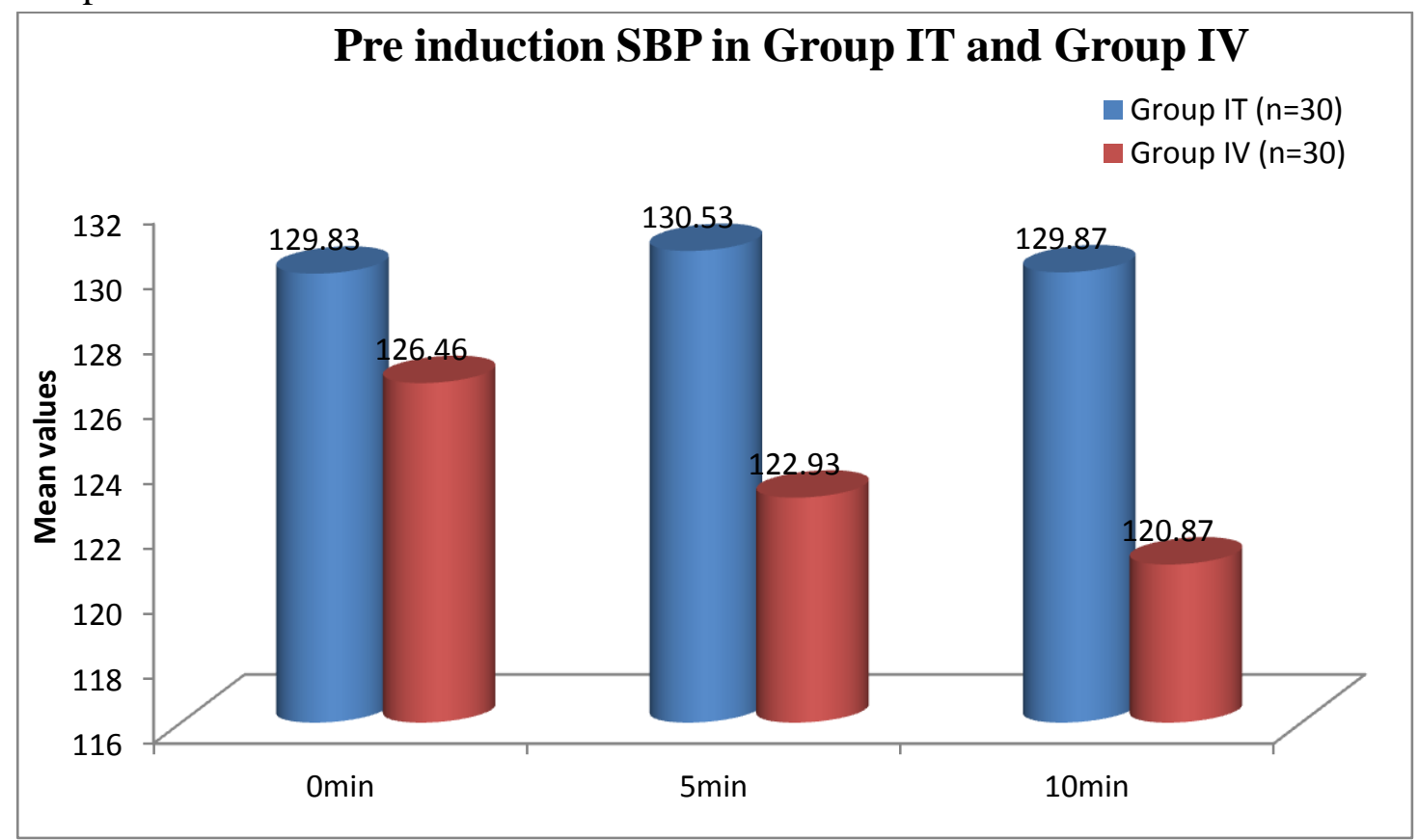

Graph 3-Pre induction DBP in both groups

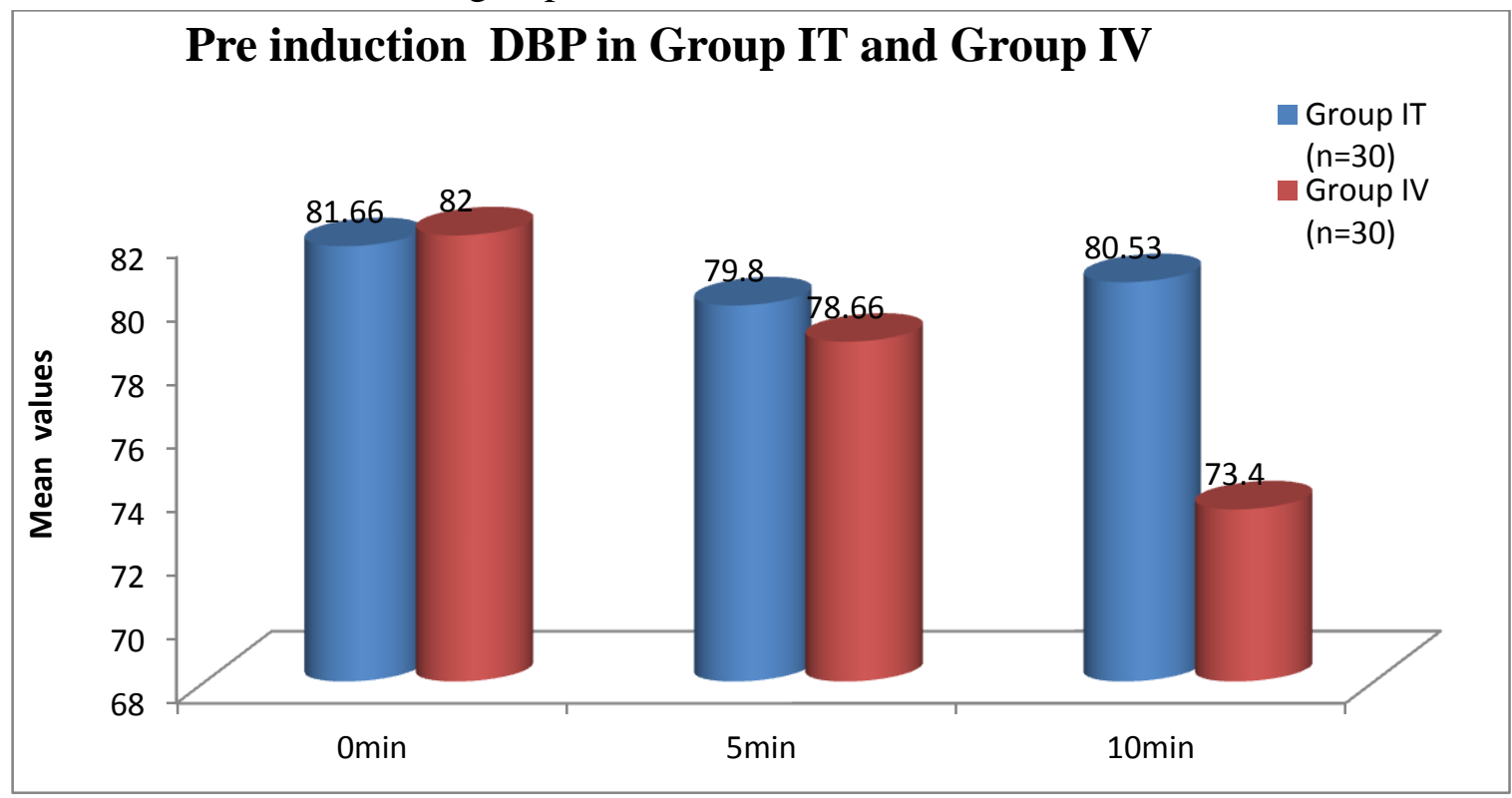

Table No.2 Sensory onset (sec)\&Motor onset (sec) in Group IT and Group IV:

\begin{tabular}{|l|c|c|c|c|}
\hline & Group IT $(\mathrm{n}=30)$ & Group IV $(\mathrm{n}=30)$ & $\begin{array}{c}\text { Student's } \\
\text { Unpaired 't' } \\
\text { test value }\end{array}$ & $\begin{array}{c}\text { 'p' value and } \\
\text { significance }\end{array}$ \\
\cline { 2 - 5 } & Mean \pm SD & Mean \pm SD & 0.97 & $\mathrm{p}=0.12$ \\
\hline Sensory onset & $172.97 \pm 15.98$ & $185.13 \pm 37.44$ & 0.82 & $\mathrm{p}=0.14$ \\
\hline Motor onset & $334.87 \pm 16.87$ & $340.70 \pm 18.17$ & & \\
\hline
\end{tabular}

Table No.3: Sensory recovery (min)\& Motor recovery (min) in Group IT and Group IV:

\begin{tabular}{|l|c|c|c|}
\hline & Group IT $(\mathrm{n}=30)$ & Group IV $(\mathrm{n}=30)$ & \multirow{2}{*}{ ' $\mathrm{p}$ ' value } \\
\cline { 2 - 3 } & Mean \pm SD & Mean \pm SD & \\
\hline Sensory recovery $(\mathrm{min})$ & $216.60 \pm 17.18$ & $183.90 \pm 13.21$ & $\mathrm{p}=0.001$ \\
\hline Motor recovery & $185.67 \pm 16.26$ & $164.77 \pm 14.93$ & $\mathrm{p}=0.001$ \\
\hline
\end{tabular}




\section{JMSCR Vol||05||Issue||01||Page 15741-15753||January}

Table No.4: Duration of complete analgesia in Group IT and Group IV:

\begin{tabular}{|l|c|c|c|c|}
\hline & Group IT $(\mathrm{n}=30)$ & Group IV $(\mathrm{n}=30)$ & $\begin{array}{c}\text { Student's } \\
\text { Unpaired 't' test } \\
\text { value }\end{array}$ & 'p' value \\
\cline { 2 - 3 } & Mean \pm SD & Mean \pm SD & 2.59 & $\mathrm{p}=0.009$ \\
\hline Duration of complete analgesia & $258.47 \pm 11.54$ & $251.86 \pm 10.83$ & \\
\hline
\end{tabular}

Table No.5: Duration of effective analgesia in Group IT and Group IV:

\begin{tabular}{|l|c|c|c|c|}
\hline & $\begin{array}{c}\text { Group IT } \\
(\mathrm{n}=30)\end{array}$ & Group IV $(\mathrm{n}=30)$ & $\begin{array}{c}\text { Student's } \\
\text { Unpaired 't' } \\
\text { test value }\end{array}$ & 'p' value \\
\cline { 2 - 5 } & Mean \pm SD & Mean \pm SD & 1.03 & $\mathrm{p}=0.11$ \\
\hline Duration of effective analgesia & $123.41 \pm 12.48$ & $126.78 \pm 11.97$ & 1.03 \\
\hline
\end{tabular}

Graph 4-Comparison of Intra operative HR

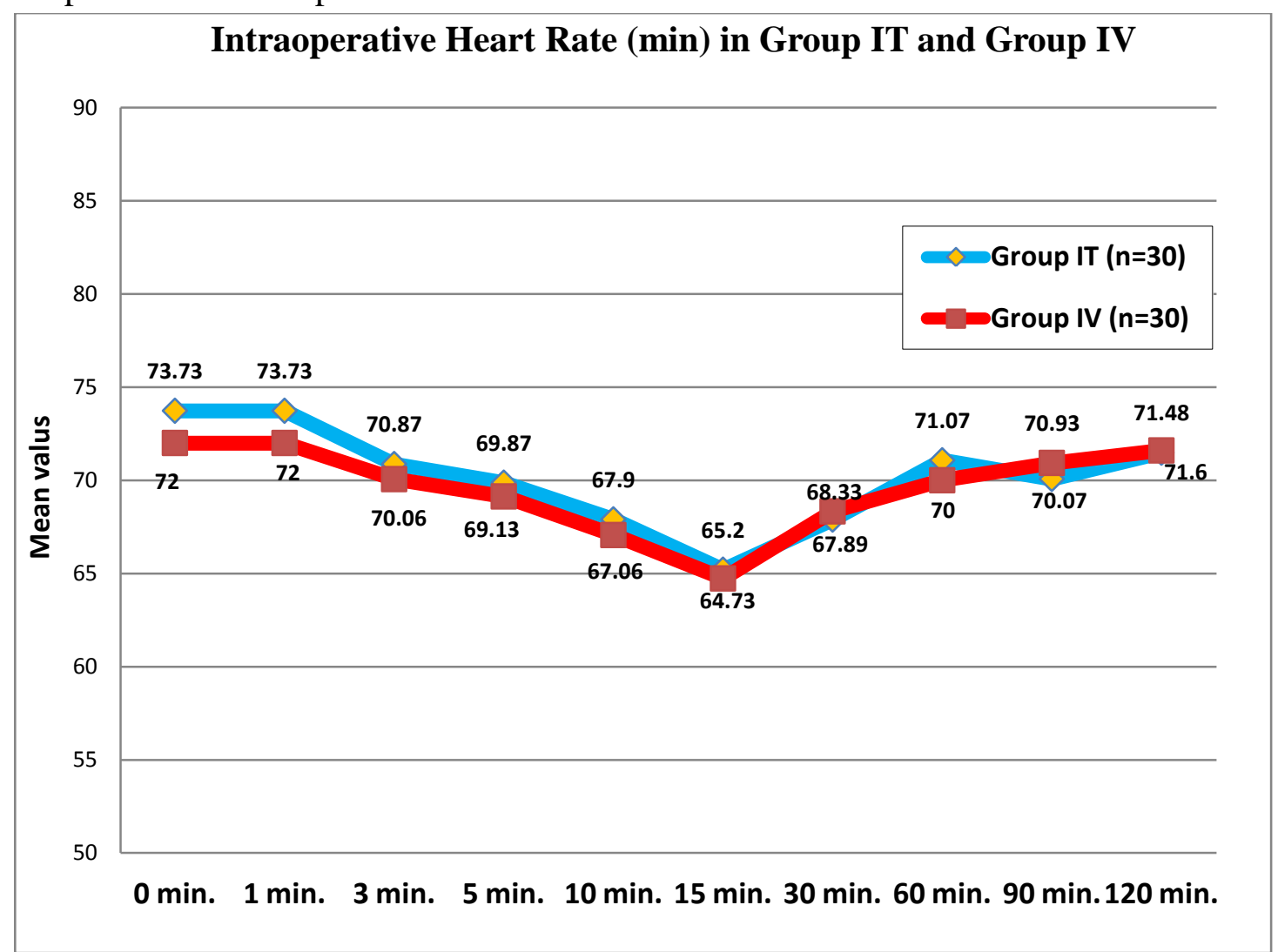


Graph 5-Comparison of Intra operative SBP

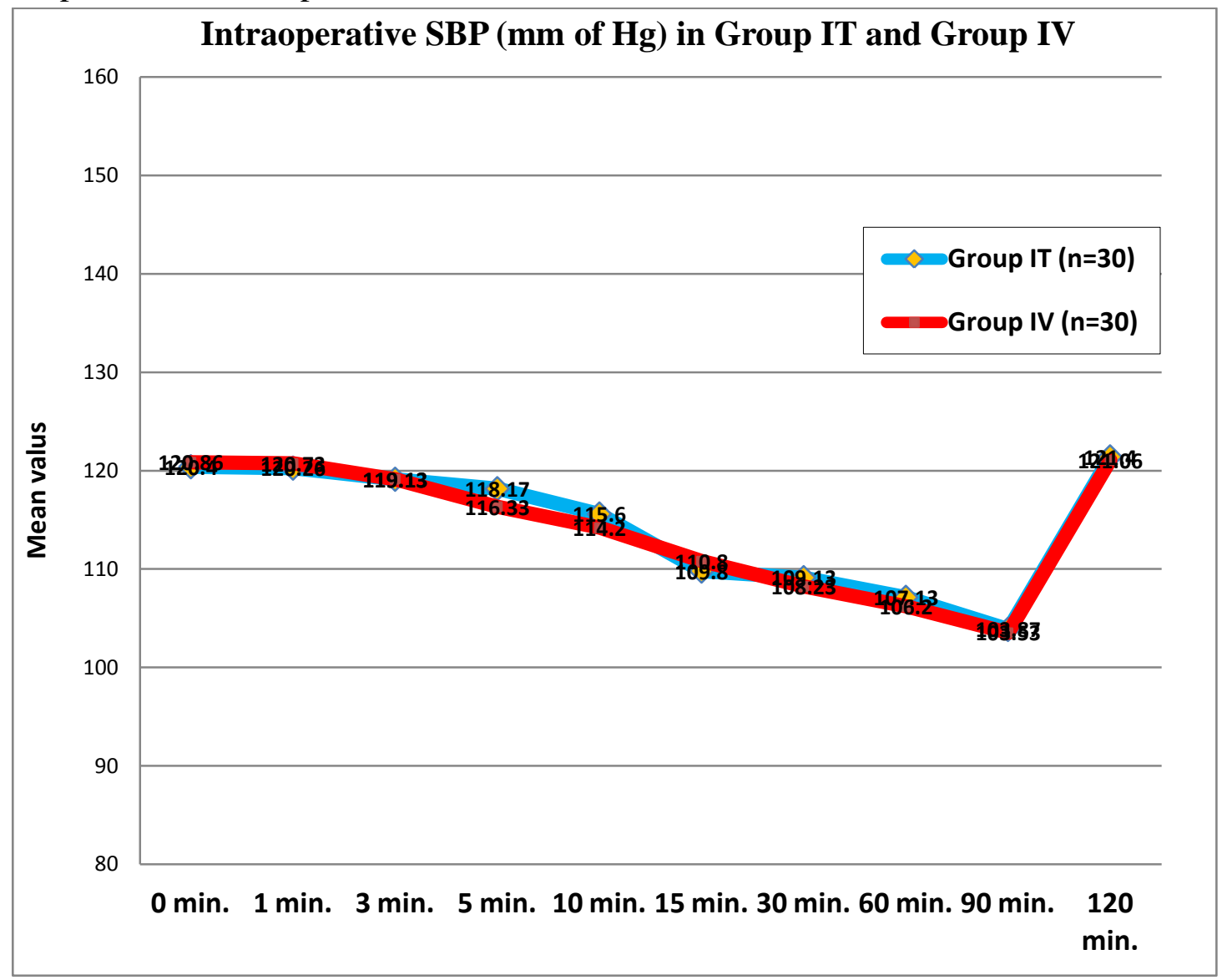

Graph 6- Comparison of Intra operative DBP

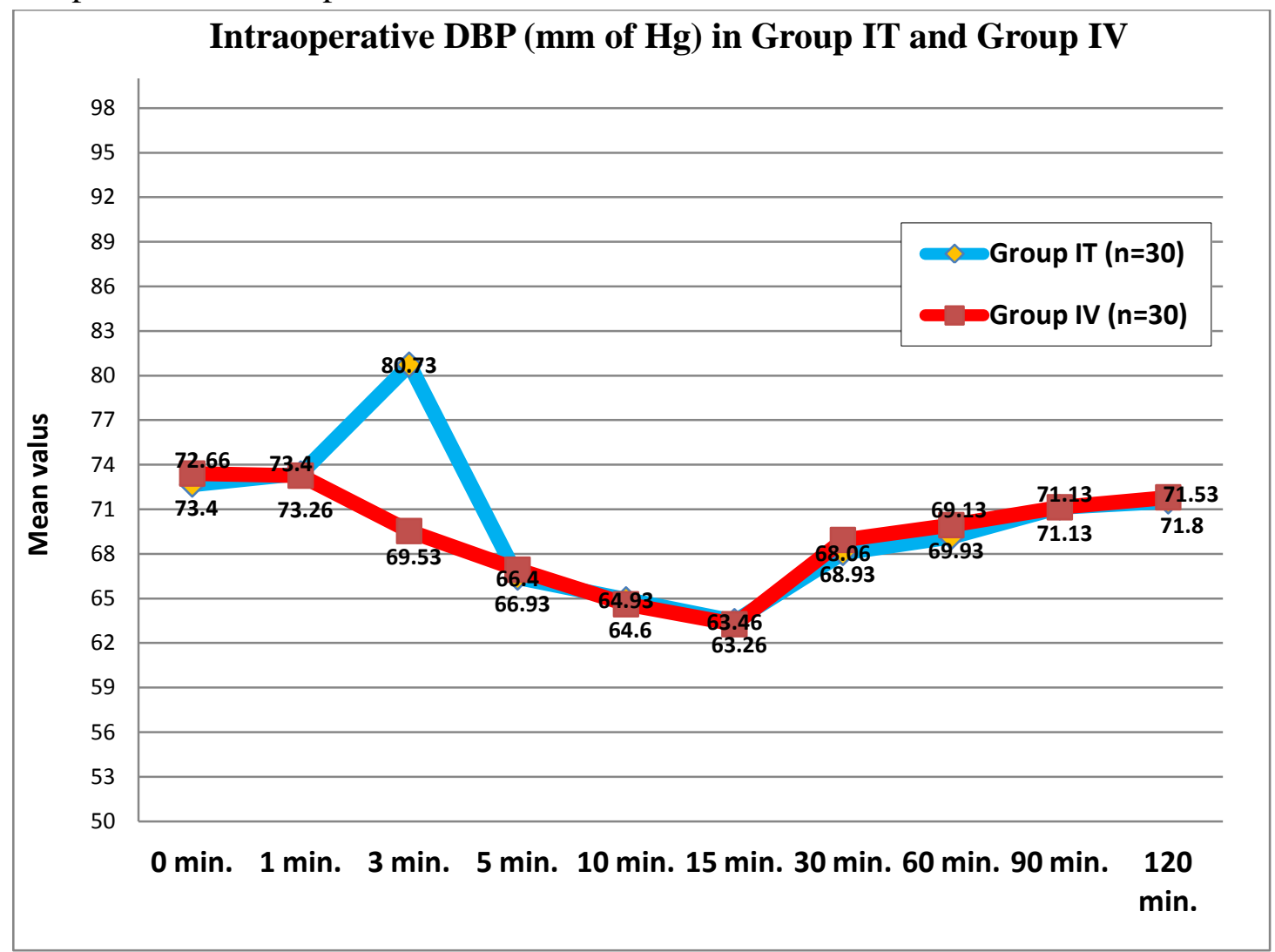




\section{JMSCR Vol||05||Issue||01||Page 15741-15753||January}

Table No.6: Ramasay sedation score in Group IT and Group IV:

\begin{tabular}{|c|c|c|c|c|}
\hline \multirow[t]{2}{*}{$\begin{array}{l}\text { Ramasay sedation } \\
\text { score }\end{array}$} & Group IT $(n=30)$ & Group IV $(n=30)$ & \multirow{2}{*}{$\begin{array}{l}\text { Student's } \\
\text { Unpaired 't' } \\
\text { test value }\end{array}$} & \multirow[t]{2}{*}{ 'p' value } \\
\hline & Mean \pm SD & Mean \pm SD & & \\
\hline 0 min. & $1.00 \pm 0.0$ & $1 \pm 0.55$ & 0 & $\mathrm{p}=1$ \\
\hline $10 \mathrm{~min}$. & $1 \pm 0.21$ & $3 \pm 0.78$ & 5.69 & $\mathrm{p}=0.001$ \\
\hline $30 \mathrm{~min}$. & $2 \pm 0.47$ & $4 \pm 0.43$ & 2.09 & $\mathrm{p}=0.01$ \\
\hline $60 \mathrm{~min}$. & $2 \pm 0.40$ & $3 \pm 0.71$ & 0.72 & $\mathrm{p}=0.01$ \\
\hline $90 \mathrm{~min}$. & $2 \pm 0.54$ & $3 \pm 0.36$ & 0.72 & $\mathrm{p}=0.32$ \\
\hline
\end{tabular}

Graph 7-Comparison of Ramasay sedation score

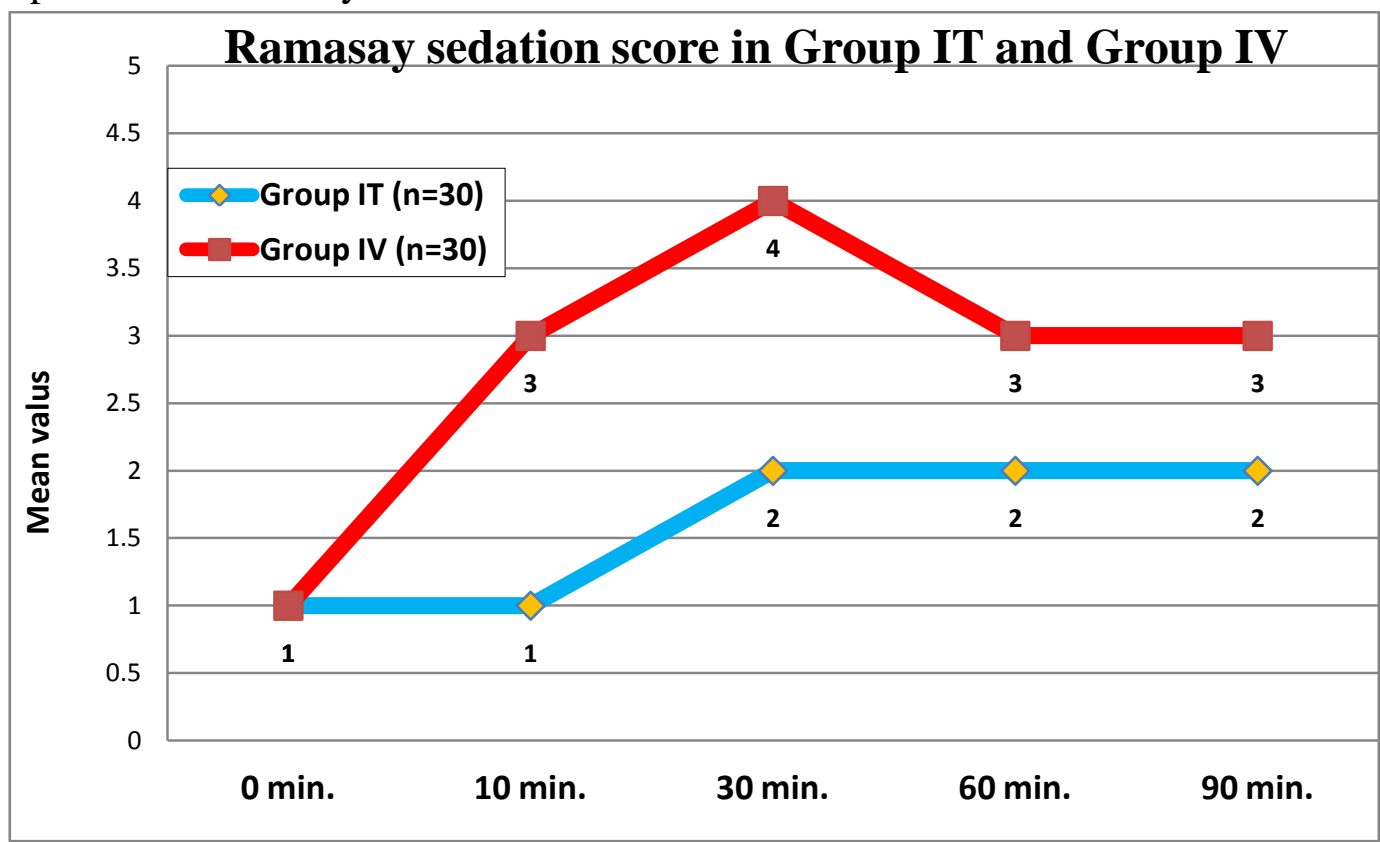

Graph 8- Comparison of Post op VAS score

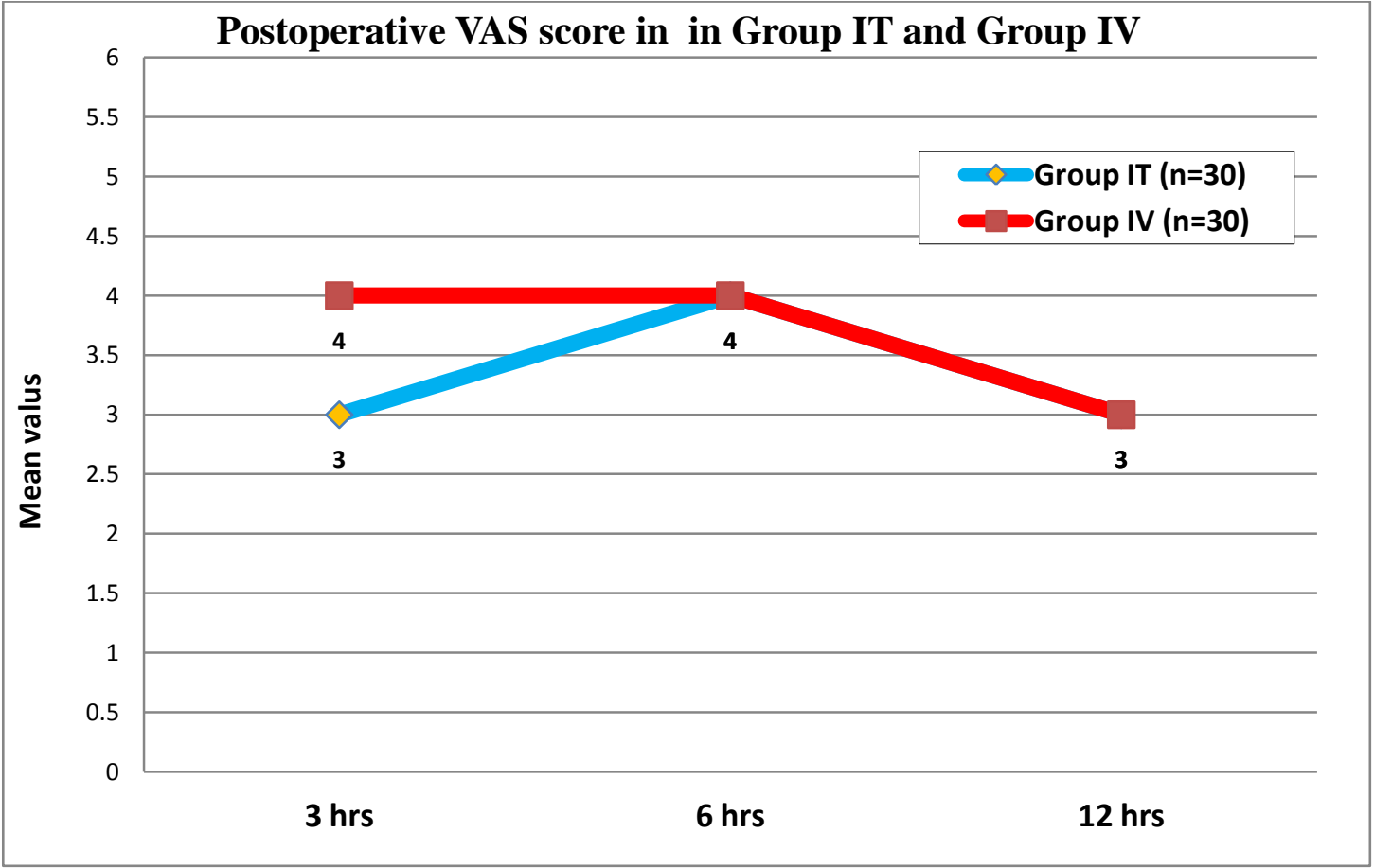


Graph 9-Comparison of highest sensory level

\section{Highest sensory level in Group IT and Group IV}

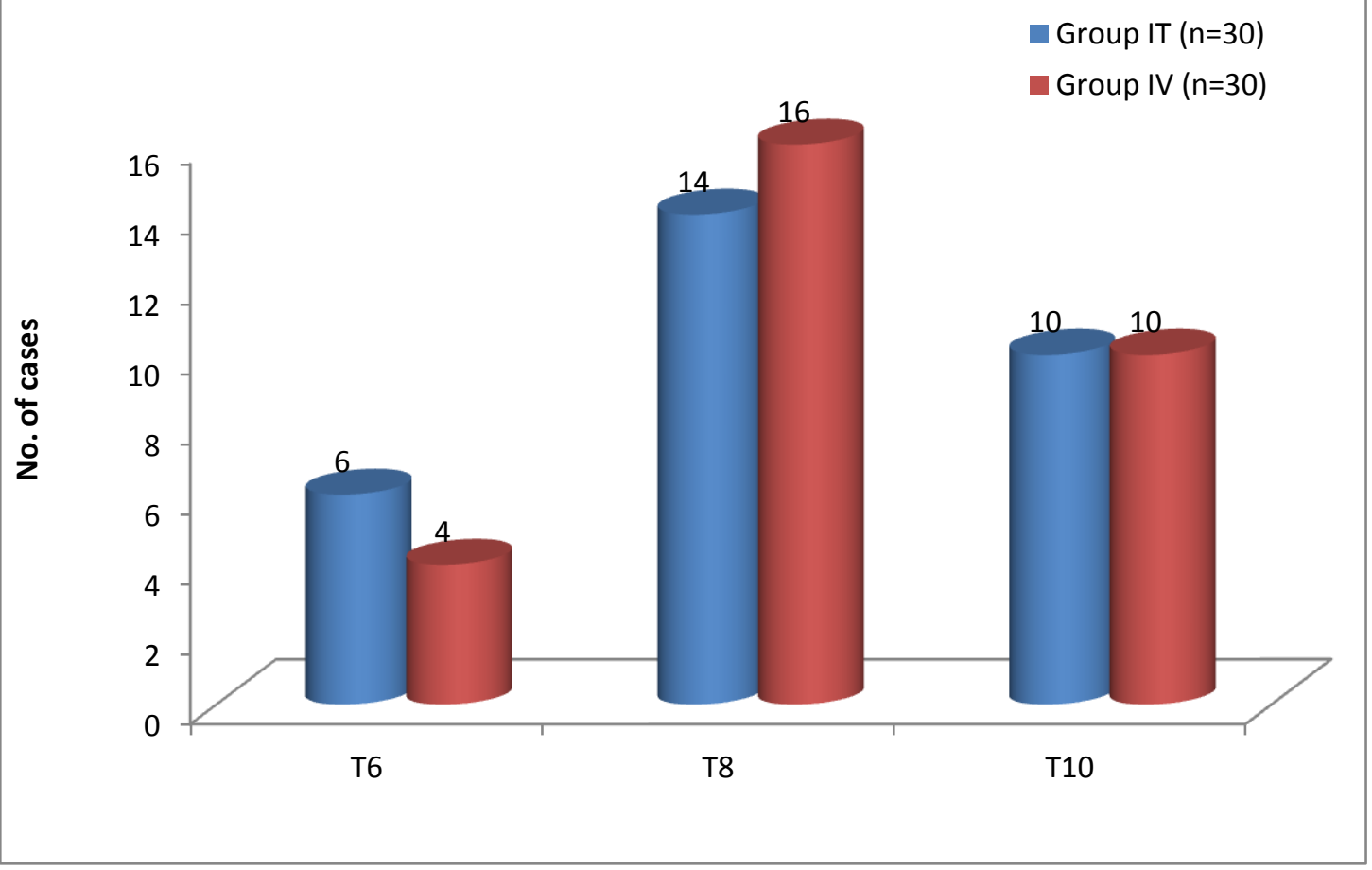

Graph 10-Comparison of side effects

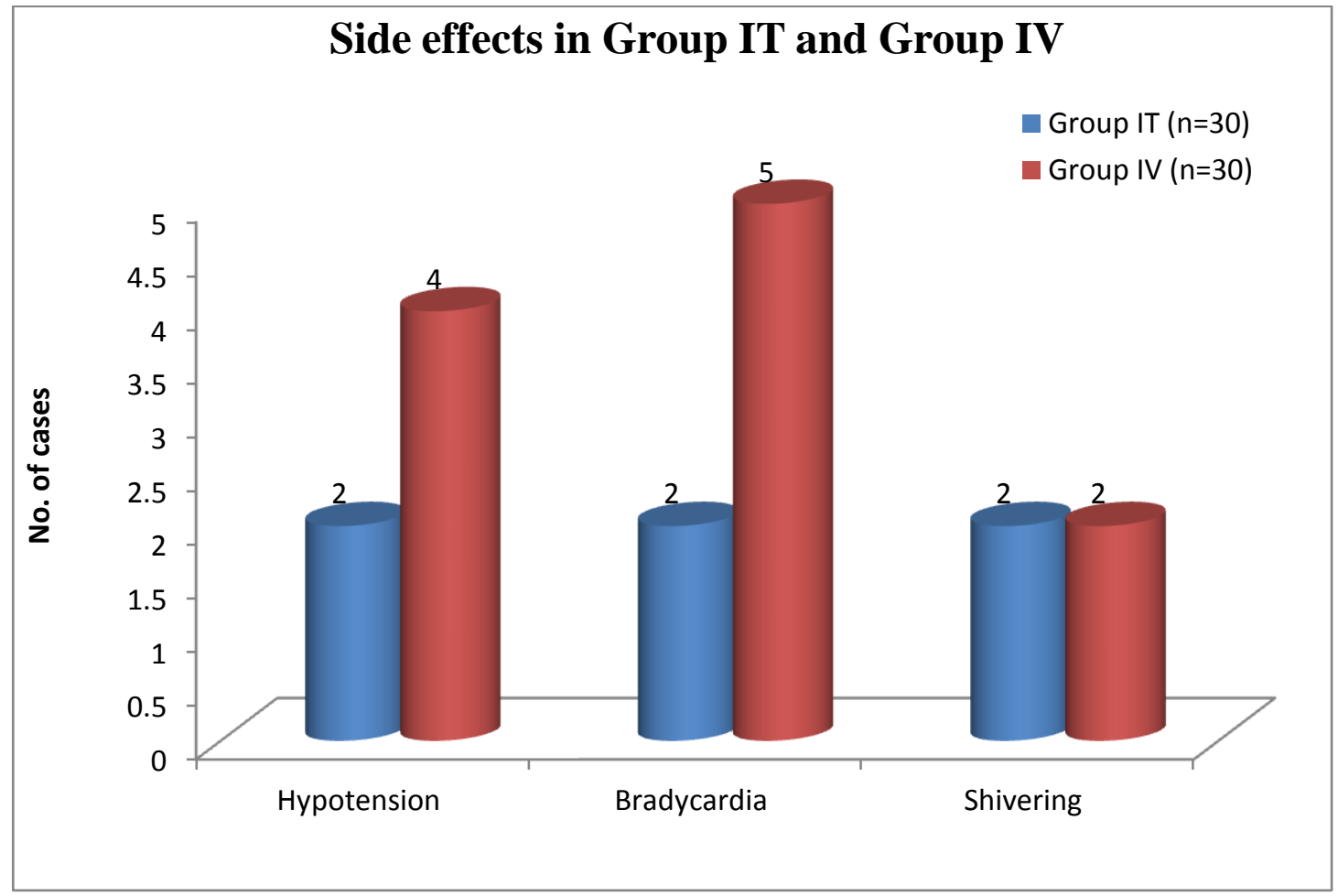

\section{Discussion}

Clonindine an alpha2 agonist is widely used by oral, intrathecal and intravenous routes as an adjuvant to regional anaesthesia. Recent studies have shown the efficacy of both intrathecal and intravenous dexmedetomidine in prolonging spinal anaesthesia. Dexmedetomdine is a more suitable adjuvant to spinal anaesthesia compared to clonidine as it has more sedative and analgesic effects due to its more selective alpha 2 receptor 
agonist activity. Systemic and intrathecal injection of dexmedetomidine produces analprolongspigesia by acting at spinal level, laminae VII and VIII of ventral horns. The drug also acts at locus ceruleus and dorsal raphe nucleus to produce sedation and analgesia. This supra spinal action explains the prolongation of spinal anaesthesia after intravenous dexmedetomidine.

Sensory blockade- It was found that dexmedetomidine whether administered intravenously or intrathecally did not accelerate the onset of spinal sensory anaesthesia (p-0.12) or affect the maximum block level but significantly prolonged the duration of spinal anaesthesia, which was significantly longer in the IT group. It was also found that the time to reach $\mathrm{Br} 3$ motor block was significantly shorter in both IT and IV groups but with no statistically significant difference between each other. This study also found that dexmedetomidine intravenously or intrathecally extended the duration of bupivacaine motor block and it was significantly longer in the IT group compared with the IV group. Kalso et $a l^{10}$ showed that a small intrathecaldose of dexmedetomidine ( $3 \mathrm{mcg}$ ), used in combination with bupivacaine in spinal anaesthesia, produced ashorter onset of motor block and a prolongationin the duration of sensory and motor block, with hemodynamic stability and no sedation. Results of the study conducted by Harsooretal ${ }^{11}$ are in agreement with our study. They studied the effect of supplementation of low-dose IV dexmedetomidine (which was given as IV bolus $0.5 \mathrm{mcg} \mathrm{kg}-1$ then infusion $0.5 \mathrm{mcg} \mathrm{kg}-1 \mathrm{~h}-1$ ) on characteristics of bupivacaine spinal anaesthesia. They reported that administration of IV dexmedetomidine during intrathecal block fastened the onset of sensory block and prolonged the duration of sensory and motor block with satisfactory arousable sedation.

Motor blockade- In the present study there was no significant difference in time taken for motor blockade to reach modified $\mathrm{Br} 3$ in both the groups [334.87 \pm 16.87 seconds in IT group compared to $340.70 \pm 18.17 \mathrm{~min}$ in IV group $\mathrm{P}$ value 0.146]. However, the regression time to reach the modified $\mathrm{Br} 0$ scale was significantly prolonged in IT group $[185.67 \pm 16.26 \mathrm{mins}]$ compared to IV group [164.77 \pm 14.93 minutes] $\mathrm{P}$ value 0.007 . Delay in motor block regression to $\mathrm{Br}$ 0 was also reported in previous studies. Kaya et $a l^{8}$ reported that the use of a single dose of 0.5 $\mu \mathrm{g} / \mathrm{kg}$ of dexmedetomidine did not affect the duration of motor blockade. Harsooret $a l^{11}$ investigated the facilitator effects of IV administration of dexmedetomidine in comparison with placebo on single-injection local anaestheticbased spinal anaesthesia. They reported that sensory block was prolonged by at least 34\%, motor block duration was prolonged by at least $17 \%$, and time to first analgesic request was increased by at least 53\%. Transient reversible bradycardia was increased in the dexmedetomidine group, but there was no difference in the incidence of hypotension or postoperative sedation.

Effect on heart rate and blood pressure-There was fall in HR and BP preoperatively in IV group. Fall in HR was significant in IV group compared to IT group (0.009). But there was no change in intraoperative HR in our study. In IT group there was no significant decrease or increase in intraoperative HR (0.14).Also in group IV there was no significant decrease or increase in intraoperative HR (0.14). Results found were similar to those found in studies done byHamed M.S. etal ${ }^{12}$ showed that the incidence of bradycardia was higher in studies where the dexmedetomidine initial loading dose was infused over a short duration (5 min). However, bradycardia was transient and reversed with IV atropine. In our study, the loading dose was infused over 10 minutes and there were no statistically significant differences (1 vs 3 vs 3 ) among the three groups. Hamed M.S. etal ${ }^{12}$ with respect to the hemodynamic variables measured during the intraoperative period, the mean values of the HR were significantly decreased starting at 20 minutes until 60 minutes in group IV in comparison with the other two groups $(P<0.05)$. There were no significant differences between 
groups in the HR values recorded during the postoperative period $(P>0.05)$. Systolic and diastolic BP values were comparable among the groups throughout the study period.

\section{Ramasaysedation score- In our study} intraoperative Ramsay sedation scores were significantly higher IV dexmedetomidine group [P $0.001]$ as compared to IT group. Maximum scores in IV group ranged from 4-5 with a mean of 4.43. However there was no significant difference in sedation scores between the groups in the postoperative period. Maximum scores in control group ranged from 2-3 with a mean of 2.09. However there was no significant difference in sedation scores between the groups in the postoperative period. Ramsay sedation score was 2 in all patients in control group and ranged from 2-5 in dexmedetomidine group in the study done by Al Mustafa et $\mathrm{al}^{13}$, the maximum score was 5 in $12 \%$ of patients, 4 in $79 \%$ of patients and 3 in $4 \%$ of patients. The maximum mean score of sedation $[3.96 \pm 0.55]$ was attained 30 minutes after starting dexmedetomidine infusion. Hong et $\mathrm{al}^{14}$ noted that the median sedation scores during surgery were 4 in the dexmedetomidine group and 2 in the control group ( $\mathrm{P}$ value $<0.001)$. A significantly higher average sedation score in dexmedetomidine group was also reported by others. Also in studies by Hong et $\mathrm{al}^{14}$ who used higher doses of dexmedetomidine and noted excessive sedation in 3 out of 25 and 2 out of 26 patients respectively in their study, none of our patients had RSS greater than 3 at any point of observation highlighting the advantage of lower dose. Kaya et $\mathrm{al}^{8}$ also had similar observations regarding sedation in their study. MiHayeon Lee etal found that RSS were significantly increased in the dexmedetomidine groups than in the control group after following injection of dexmedetomidine. In addition, in the D-1 groups the RSS were significantly higher than in the D- 0.5 group. The excessive sedation ( $\mathrm{RSS}>4$ ) was observed in 1 of 20 patients and 5 of 20 patients in the D- 0.5 and D-1 groups, respectively. However, there were no patients with oxygen desaturation among the three groups. The regression time of the RSS $(<3)$ was $83.6 \pm 40.4$ and $89.9 \pm 42.7$ in the D-0.5 and D-1 groups, respectively.

Effect on analgesia- The mechanism of action by which intrathecal $\alpha_{2}$ - adrenoceptor agonists prolong the motor and sensory block of local anaesthetics is not well known. The local anaesthetics act by blocking sodium channels, whereas the $\alpha_{2}$-adrenoceptor agonist acts by binding to pre-synaptic C-fibres and post-synaptic dorsal horn neurons. Dexmedetomidine inhibits the release of substance $P$ from the dorsal horn of the spinal cord, leading to primary analgesic effects The analgesic action of intrathecal $\alpha_{2}$-adrenoceptor agonists is by depressing the release of C-fibre transmitters and by hyperpolarisation of post-synaptic dorsal horn neurons.It may be an additive or synergistic effect secondary to the different mechanisms of action of the local anaesthetics and the $\alpha_{2}$-adrenoceptor agonist as studied by Kaya et $a l^{8}$. This antinociceptive effect may explain the prolongation of the sensory block when added to spinal anaesthetics. The prolongation of the motor block of spinal anaesthetics may result from the binding of $\alpha_{2}$-adrenoceptor agonists to motor neurons in the dorsal horn. In our study duration complete analgesia was 258.47 in group A while in groupB it was 251.86.p -0.0097, thus there was significant difference between both. Thus duration of analgesia provided by IT dexmedetomidine is better than IV dexmedetomidine. Duration of effective analgesia was also more in IT group but there was no significant difference between both,p-0.119. Our study results were similar with previous study results. In studies conducted by Hamedetal $^{12}$,the time to first analgesic needed was significantly prolonged in groups IV and IT in comparison with group $\mathrm{B}$, without significant difference between groups IV and IT. The mean total consumption IV tramadol postoperatively in the first 24 hours was significantly decreased in groups IV and IT in comparison with group B, without significant difference between groups IV and IT. 
Similar results were found by study done by Kalsoetal $^{10}$, also in study by Fares M A etal ${ }^{15}$ found that dexmedetomidine $5 \mathrm{mcg}$ given intrathecally improves the quality and the duration of postoperative analgesia and also provides an analgesic sparing effect in patients undergoing major abdominal cancer surgery. Furthermore, the addition of intrathecal fentanyl $25 \mathrm{mcg}$ has no valuable clinical effect. Thus analgesia provided by IT group is better than IV group.

Post-operative vas- In our study there was no significant post-operative vas and our results were similar with related studies.

Side effects- Incidence of hypotension was seen $6 \%$ cases in IT group while in IV group incidence was $13 \%$.Incidence of bradycardia was also $6 \%$ in IT group while in IV group it was significantly more that is $16 \%$. while incidence of shivering was seen only 2 cases each out of 30 in both the groups. Thus in our study incidence of bradycardia and hypotension was more in IT group than IV group, which were treated with atropine and phenylephrine respectively. Our study results were similar in accordance with previous studies.

Hamedetal $^{12}$ found that with respect to haemodynamics, the HR values were significantly decreased starting at 20 min until60 minutes in group IV in comparison with the other two groups, but BP values were comparable hroughout the study period. Abdallah FW, when IV dexmedetomidine accompanied spinal anaesthesia, use of dexmedetomidine was associated with a 3.7-fold increase in transient reversible bradycardia. Al-Ghanemet al ${ }^{16}$ have reported the use of dexmedetomidine to be associated with a decrease in HR and BP. In their study, only two cases of bradycardia and hypotension were noticed. The incidence of nausea and vomiting were few and comparable in both groups.Similar results were noted in previous studies.

\section{Conclusion}

Intrathecal dexmedetomidine significantly prolongs the duration of sensory and motor block of bupivacaine spinal anaesthesia as compared to intravenous dexmedetomidine, with preserved hemodynamic stability.

\section{References}

1. Davies NJH, Cashman JN. Techniques in regional anaesthesia. Lee's Synopsis of Anaesthesia. $13^{\text {th }}$ ed. Elsevier, 2006; 40170.

2. Gupta R, Verma R, Bogra R, Kohli M, Raman R, Kushwaha JK. A comparative study of intrathecaldexmedetomidine and fentanyl as adjuvants to bupivacaine. J AnaesthClinPharmacol. 2011;27:339-43.

3. Isguzar O, Bans S, Bozkurt A, Can B, Bilge $\mathrm{S}$, Ture $\mathrm{H}$. Evaluation of Antinociceptive and Neurotoxic Effects of IntrathecalDexmedetomidine in Rats. Balkan Med J 2012;29:354-58.

4. Tamsen A, Gordh T. Epidural clonidine produces analgesia. Lancet 1984;

5. Dobrydnjov I, Axelsson K, Thorn S-E, et al. Clonidine combinedwith small-dose bupivacaine during spinal anesthesia for inguinalherniorrhaphy: a randomized double-blinded study. AnesthAnalg 2003;96:1496-1503.

6. Strebel S, Gurzeler J, Schneider M, Aeschbach A, Kindler C. Smalldoseintrathecal clonidine and isobaric bupivacaine for orthopedic surgery: adoseresponse-study. AnesthAnalg 2004; 99:1231-1238.

7. Kanazi GE, Aouad MT, Jabbour-Khoury SI, Al Jazzar MD, et al. Effect of low-dose dexmedetomidine or clonidine on the characteristics ofbupivacaine spinal block. ActaAnaesthesiolScand 2006; 50:222-227

8. Kaya FN, Yavascaoglu B, Turker G, et al. Intravenous dexmedetomidine,but not midazolam, prolongs bupivacaine spinal anesthesia. Can J Anaesth 2010; 57:39-45

9. Elcicek K, Tekin M, Kati I. The effects of intravenous dexmedetomidineonspinal 
hyperbaric ropivacaineanesthesia. J Anesth 2010; 24:544-548

10. Kalso EA, Poyhia R, Rosenberg PH. Spinal antinociception by dexmedetomidine, a highly selective $\square 2$-adrenergic agonist. PharmacolToxicol 1991; 68:140-

11. Harsoor SS, Rani DD, Yalamuru B, et al. Effect of supplementation of low dose intravenous dexmedetomidine on characteristics of spinalanaesthesia with hyperbaric bupivacaine. Indian J Anaesth 2013; 57: 265-269.

12. Hamed AM, Talaat SM. Effect of intravenous versus intrathecal low-dose dexmedetomidine on spinal block in lower limb orthopedic surgery. Ain-Shams J Anaesthesiol 2014;7:205-10.

13. Al-Mustafa MM, Badran IZ, Abu-Ali HM, et al. Intravenous dexmedetomidine prolongs bupivacaine spinal analgesia. Middle Eas J Anesthesiol 2009; 20:225-231.

14. Hong JY, Kim WO, Yoon Y, Choi Y, Kim $\mathrm{SH}$, Kil HK. Effects of intravenous dexmedetomidine on low-dose bupivacaine spinal anaesthesia in elderly patients. ActaAnaesthesiolScand 2012; 56:382-7.

15. Mohamed AA, Fares KM, Mohamed SA. Efficacy of IY, Qatawneh AM, Abu-Ali HM. Effect of adding dexmedetomidine versus fentanyl to intrathecal bupivacaine on spinal block characteristics in gynecological procedures: A double blind controlled study. Am. J. Appl. Sci., 6, 882-887 (2009).

16. Al-Ghanem S M., Massad IM., Al-Mustafa M M., Al- Zaben K R.,Qudaisat I Y, Qatawneh A M, Abu-Ali H M. Effect of Adding Dexmedetomidine versus Fentanyl to Intrathecal Bupivacaine on Spinal Block Characteristics in Gynecological Procedures: Am J Appl Sci. 2009;6:882- 887. 